\title{
SEM and EBSD Characterization of Cold-Sprayed Chromium Coatings on Zircaloy-4
}

\author{
Jonas Heuer, Gene Lucadamo and Paolo Zafred
}

Naval Nuclear Laboratory, West Mifflin, Pennsylvania, United States

Although zirconium (Zr) alloys have been successfully used in commercial light water reactors (LWRs) for several decades [1], the earthquake and tsunami that led to the 2011 Fukushima-Daiichi accident in Japan have raised concerns about the durability of $\mathrm{Zr}$ alloys during a loss of coolant accident (LOCA) [2]. Under these conditions, $\mathrm{Zr}$ alloys undergo an extremely exothermic reaction from rapid oxidation in air/steam while simultaneously generating potentially-dangerous quantities of hydrogen gas [3]. To mitigate these concerns, Congress directed the Department of Energy to spearhead an industry-led accident tolerant fuel (ATF) program to develop materials that are better suited to withstand accident scenarios. Long-term options under investigation include complete replacement of $\mathrm{Zr}$ alloy claddings with alternate materials having better LOCA tolerance, whereas near-term options include the deposition of oxidation-resistant materials on current $\mathrm{Zr}$ alloys [4-6]. The near-term options are particularly attractive because they do not necessitate major design changes to existing commercial reactors [4], and deposition of thin protective layers using cold-sprayed coatings is both cost effective and efficient for industrial-scale production [6]. This paper provides an initial detailed characterization of as-deposited cold-sprayed chromium (Cr) coatings on Zircaloy-4 (Zr-4) using advanced microstructural characterization methods. These methods include scanning electron microscopy (SEM) and electron backscattered diffraction (EBSD) analysis with the goals of characterizing both the applied coatings as well as the interfaces with the $\mathrm{Zr}-4$ substrate.

Coatings were applied using a commercial cold-spray system. $\mathrm{Cr}$ was deposited at high velocities by feeding powder in a heated helium carrier gas through a nozzle which was translated across the surface of a Zr-4 substrate. Coatings were applied in either a single pass (1-pass) layer having a thickness of $\sim 60 \mu \mathrm{m}$ or in a double pass (2-pass) layer having a total thickness of $\sim 130 \mu \mathrm{m}$. The as-deposited films were subsequently characterized in a Thermo Scientific Scios-2 focused-ion-beam scanning electron microscope equipped with an Oxford Instruments Symmetry EBSD detector. Cross sections of the deposited films were prepared for examination by mechanically polishing the cut surfaces with 1200 grit silicon carbide paper and then electropolishing the resulting surfaces using an electrolyte composed of $20 \%$ perchloric acid and $80 \%$ methanol. Electropolishing was performed at $-50^{\circ} \mathrm{C}$ for 30 seconds at a fixed voltage of $30 \mathrm{~V}$ and a current density $4.3 \mathrm{~A} / \mathrm{cm}^{2}$ to provide surfaces adequate for EBSD analysis in both the Cr coatings and $\mathrm{Zr}-4$ substrate.

The Cr coatings in both the 1-pass and 2-pass regions were found to have a distinct morphology that is likely related to the high-speed impact of $\mathrm{Cr}$ particles that occurs during the cold-spray process. The coatings have a highly-deformed microstructure (Figure 1A) consisting of flattened nodules (also known as splats) which are approximately $20 \mu \mathrm{m}$ long and $10 \mu \mathrm{m}$ high. These sizes are consistent with the $\mathrm{Cr}$ powder used for the spray-coating process. The nodules often contain a small number of highly-deformed larger grains $(\sim 10 \mu \mathrm{m}$ in size $)$ surrounded by a large number of less-deformed smaller grains $(\leq 1 \mu \mathrm{m}$ in size). The smaller grains may result from dynamic recrystallization that occurs during the spray-coating process [6]. No significant crystallographic texturing was noted in either the 1-pass or 2-pass regions, and no distinct delineation was observed in the 2-pass Cr layers to distinguish between the two coating passes.

The interface between the Cr coatings and the underlying $\mathrm{Zr}-4$ metal was also found to contain a number of notable features. First, no voids or microcracks are observed at this interface. This suggests the coatings 
are adherent, and independent mechanical testing using ASTM C633 standard adhesion testing confirms this. Second, the interface itself is not entirely linear at high magnifications, and fingers of $\mathrm{Zr}-4$ metal appear to extend around individual $\mathrm{Cr}$ nodules. This suggests that the powder particles at the interface are embedded in the original surface of the $\mathrm{Zr}-4$ substrate. Third, there are some deformation features in the $\mathrm{Zr}-4$ metal near the interface with the coating layers (Figure 1B) that extend up to $20 \mu \mathrm{m}$ into the substrate. These deformation features appear in the form of either slip bands or deformation twins, and they often extend from the larger embedded $\mathrm{Cr}$ particles. The flow of $\mathrm{Zr}-4$ substrate material around the harder $\mathrm{Cr}$ particles embedded at the interface and the associated deformation structures in the underlying $\mathrm{Zr}-4$ metal suggest that these features arise during the spray-coating process from the high-speed impact of powder particles on the $\mathrm{Zr}-4$ metal.
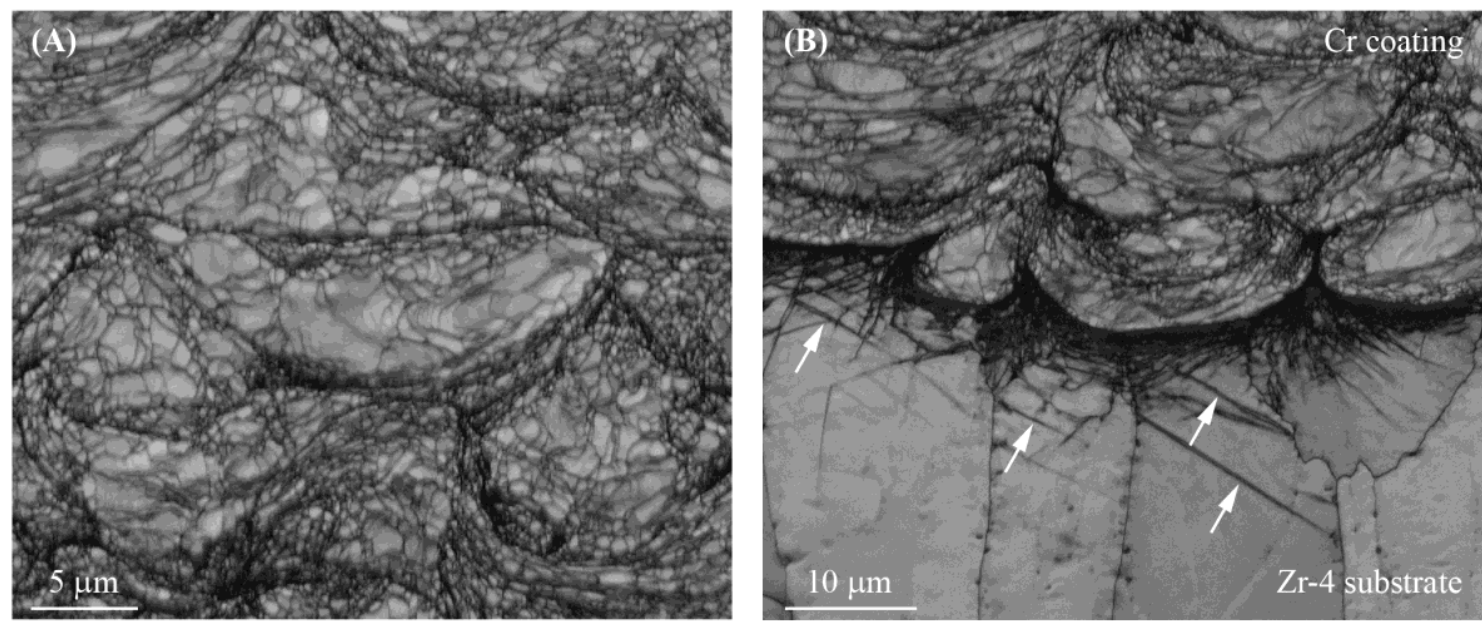

Figure 1. Band contrast maps showing (A) the highly deformed microstructure in as-deposited coldsprayed $\mathrm{Cr}$ coatings and (B) deformation and defect structures (see arrows) at the interface between the coating and the underlying $\mathrm{Zr}-4$ substrate.

\section{References}

[1] G Sabol et al, in Reactor Corrosion Performance of ZIRLOTM and Zircaloy-4 (1994).

[2] BA Pint et al, Metallurgical and Materials Transactions E2 (2015) 190-196.

[3] SJ Zinkle et al, Journal of Nuclear Materials 448 (2014) 374-379.

[4] B Maier et al, Journal of Nuclear Materials 519 (2019) 247-254.

[5] J Bischoff et al, Nuclear Engineering and Technology 50 (2018) 223-228.

[6] M Sevecek et al, Nuclear Engineering and Technology 50 (2018) 229-236. 